\title{
Synthesis, Characterization, and Size Control of Zinc Sulfide Nanoparticles Capped by Polyethylene Glycol
}

\author{
S.H.A. Allehyani ${ }^{1}$, R. Seoudi ${ }^{2,1}$, D.A. Said ${ }^{1,3}$, A.R. Lashin ${ }^{1,4}$, A. Abouelsayed ${ }^{2}$ \\ ${ }^{1}$ Department of Physics, College of Applied Science, Umm Al-Qura University, Makkah 21955, Saudi Arabia \\ 2 Spectroscopy Department, Physics Division, NRC, Dokki, Cairo 12622, Egypt \\ ${ }_{3}^{3}$ Physics Department, Faculty of Girls for Art, Sciences and Education, Ain Shams University, Egypt \\ ${ }^{4}$ Department of Physics, Faculty of Science, Mansoura University, Mansoura 35516, Egypt
}

(Received 26 January 2015; published online 22 August 2015)

\begin{abstract}
Zinc sulfide nanoparticles were synthesized with controllable size via chemical precipitation. highresolution transmission electron microscopy (HRTEM) and X-ray powder diffraction (XRD) showed that the samples were grown with the cubic phase; the particle size was varied by varying the molar ratios of zinc chloride and sodium sulfide in the presence of poly(ethylene glycol). The optical band gap was calculated on the basis of ultraviolet-visible spectroscopy (UV-VIS) and ranged from $4.13 \mathrm{eV}$ to $4.31 \mathrm{eV}$ depending on the particle size. Surface passivation and adsorption of poly(ethylene glycol) on the nanoparticles was explained on the basis of Fourier transform infrared measurements (FTIR).
\end{abstract}

Keywords: Chemical co-precipitation method, Zinc sulfide nanoparticles, Zinc chloride, Sodium sulfide, Polyethylene glycol; HRTEM; XRD; UV-VIS.

PACS numbers: 61.46.-w, 68.37.Yz

\section{INTRODUCTION}

Zinc sulfide (ZnS) is an important II-VI group semiconductor material, and it is a promising candidate for optoelectronic devices owing to its wide band gap for the cubic and hexagonal wurtzite phases $[1,2]$. It has better chemical stability than other chalcogenides, and it is widely used in many applications such as field effect transistors, transductors, sensors, optical coatings, light-emitting devices, solid-state solar cell windows, and photonic crystal devices [3-6]. Jayalakshmi and Rao [7] extensively studied the capabilities of $\mathrm{ZnS}$ nanoparticles for applications in areas such as non-linear optical devices and fast optical switches. ZnS nanoparticles have excellent transmission properties between $400 \mathrm{~nm}$ to $1200 \mathrm{~nm}$ as well as a high refractive index, which makes $\mathrm{ZnS}$ one of the most promising luminescent materials for novel photonic crystal devices [8]. ZnS crystals usually exhibit polymorphism with two phases: a cubic phase with an energy gap of $3.71 \mathrm{eV}$ and a hexagonal phase with an energy gap $3.77 \mathrm{eV}$ [9]. The cubic phase is more stable at low temperatures, and it is transformed into the hexagonal phase at temperatures above $1000^{\circ} \mathrm{C}$. The crystal structure of $\mathrm{ZnS}$ plays an important role in its physical and chemical properties. In the present study, $\mathrm{ZnS}$ nanoparticles capped by poly(ethylene glycol) (PEG), with controllable size and stability, were synthesized via chemical precipitation at room temperature. The effects of the molar ratios of the precursors zinc chloride $\left(\mathrm{ZnCl}_{2}\right)$ and sodium sulfide $\left(\mathrm{Na}_{2} \mathrm{~S}\right)$ on the size and morphological characteristics of the synthesized $\mathrm{ZnS}$ nanoparticles were investigated via high-resolution transmission electron microscopy (HRTEM) and X-ray powder diffraction (XRD), while their optical properties were studied using ultraviolet-visible (UV-Vis) spectroscopy.

\section{MATERIALS AND METHOD}

A simple chemical co-precipitation method was adopted to synthesize $\mathrm{ZnS}$ nanoparticles of different sizes in colloidal solution using different molar aqueous solutions of $\mathrm{ZnCl}_{2}$ and $\mathrm{Na} 2 \mathrm{~S}$ as the source materials and PEG as the capping material. In this procedure, $\mathrm{ZnCl}_{2}(0.1 \mathrm{M})$ and $\mathrm{Na} 2 \mathrm{~S}(0.1 \mathrm{M})$ were dissolved in 500 $\mathrm{ml}$ and $720 \mathrm{ml}$ of distilled water, respectively. The two solutions were stirred continuously for $30 \mathrm{~min}$. A $5 \mathrm{wt} \%$ solution of PEG was stirred to achieve complete dissolution at room temperature. For synthesized sample (S1) with a $\mathrm{Zn}^{2+}: \mathrm{S}^{2-}$ molar ratio of $1: 0.5,50 \mathrm{ml}$ of $\mathrm{Na}_{2} \mathrm{~S}$ was added drop by drop to $100 \mathrm{ml}$ of $\mathrm{ZnCl}_{2}$ under magnetic stirring; then, $70 \mathrm{ml}$ of PEG surfactant was added to the reaction medium. The white $\mathrm{ZnS}$ nanoparticles precipitated and grew slowly in the solution according to the reaction $\left(\mathrm{Zncl}_{2}+\mathrm{Na}_{2} \mathrm{~S} \rightarrow \mathrm{ZnS}+2 \mathrm{Nacl}\right)$. The precipitate was filtered and dried at $40^{\circ} \mathrm{C}$ for $36 \mathrm{~h}$ to remove any organic residue, water, and other byproducts formed during the reaction process. After sufficient drying, the precipitate was crushed into a fine powder using a mortar and pestle. To study the effects of molar ratio on the size and optical properties of the $\mathrm{ZnS}$ nanoparticles, samples with different $\mathrm{Zn}^{2+}: \mathrm{S}^{2-}$ molar ratios were prepared: S2 (1:0.7), S3 (1:1.5), S4 (1:2), and S5 (1:2.5). XRD measurements were carried out using X'PERT PRO (PANalytical, The Netherlands) with $\mathrm{Cu}-$ $\mathrm{Ka}$ radiation $(\lambda=0.15406 \mathrm{~nm})$. The X-ray generator was set to an acceleration voltage of $40 \mathrm{kV}$ and filament emission of $40 \mathrm{~mA}$. The spectra were collected in a wide-angle $\left(10^{\circ}<2 \theta<80^{\circ}\right)$ region. The specimens for TEM observations were prepared by dispersing $\mathrm{ZnS}$ powder in distilled water and dropping it on holey carbon grids. The particle morphology and pore structure were observed in detail using a high-resolution transmission electron microscope (JEOL JEM-2010) operating at $200 \mathrm{kV}$. Images were digitally recorded using a CCD camera (Keen View). The UV-Vis spectra were 
measured in the range of 1000-200 nm using a spectrophotometer (Thermo Scientific Evolution 220). The samples were prepared as suspensions using distilled water. Fourier transform infrared (FTIR) transmittance spectra of the prepared samples were measured with an FTIR spectrometer (JASCO 6100) in the midIR range using the $\mathrm{KBr}$ method.

\section{RESULTS AND DISCUSSION}

The synthesis of $\mathrm{ZnS}$ nanoparticles capped by PEG has been shown schematically in Figure 1. The hydroxyl groups of PEG can cover the surface of $\mathrm{ZnS}$ nanoparticles owing to the presence of van der Waals forces between the negatively charged oxygen groups in the molecular structure of PEG and positively charged groups that surround the surface of inert $\mathrm{ZnS}$ nanoparticles.

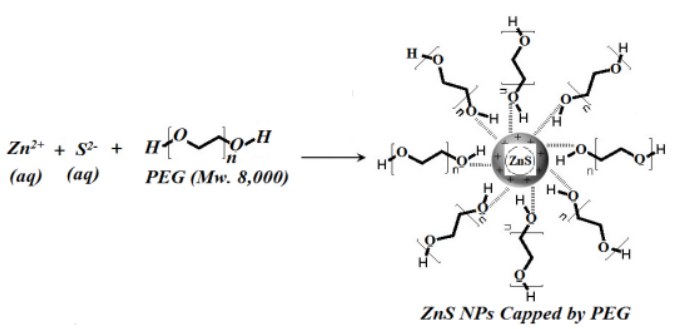

Fig. 1 -Schematic illustration showing the interaction between the hydroxyl group in polyethylene glycol with the surface of positive charge of zinc sulfide nanoparticle.

The crystallographic structure and size of nanocrystallites are studied using XRD. ZnS has two crystalline phases (zinc blend and wurtzite); both have a direct band structure. Figure 2 shows the XRD patterns for the as-prepared $\mathrm{ZnS}$ nanoparticles grown in PEG at different molar ratios of the precursors $\mathrm{ZnCl}_{2}$ and $\mathrm{Na}_{2} \mathrm{~S}$. Three diffraction peaks were observed in the diffractrogram at $2 \theta^{\circ}$ around $28.52^{\circ}, 48.13^{\circ}$, and $56.75^{\circ}$, matching with the (111), (220), and (311) crystalline planes for all the samples (S1-S5). These data can be indexed to the cubic phase with lattice constant calculated as $5.4 \AA$. The results are in good agreement with the values from the JCPDS database (card no. 050566) for $\mathrm{ZnS}$ nanoparticles. It is clear that the peaks are relatively broad, which is expected for nanoparticles of small size. The average crystallite sizes were calculated from the bandwidth of the intense peak (111) using the Debye-Scherrer equation [10, 11].

$$
d=\frac{0.9 \lambda}{\beta \cos \theta}
$$

where $d$ is the coherence length for the spherical crystalline structure, $d=3 / 4 D, D$ is the diameter of the particles, $\lambda$ is the wavelength of the X-ray $\mathrm{Cu}-\mathrm{Ka}$ radiation $(\lambda=0.15406 \mathrm{~nm}), \quad B$ is the full width at half maximum (FWHM) of the peak, and $\theta$ is the angle of diffraction. The calculated particle sizes are listed in Table (1); it can be seen that the particle size decreases with decreasing $\mathrm{Zn}^{2+}$ and increasing $\mathrm{S}^{2+}$ concentrations owing to the electronic configuration of $\mathrm{S}^{-2}\left(3 \mathrm{p}^{4}\right)$, because of which its tendency to interact with PEG and oxygen anions is greater than that of $\mathrm{Zn}^{2+}\left(3 \mathrm{~d}^{10}\right)$, which has a complete electronic configuration. The microstructure, morphology, and particle size of the $\mathrm{ZnS}$ nanoparticles prepared by precipitation under different molar ratios of the precursors are investigated using HRTEM images. Figure 3 shows the HRTEM micrographs of all the samples (S1-S5). It can be seen that the nanoparticles were formed with a nearly spherical shape. The mean particle sizes were estimated from the particle size histograms, and they are listed in Table 1. Figure 3 shows that the particle size is directly affected by the $\mathrm{Zn}^{2}: \mathrm{S}^{2-}$ ratio. The inset (Fig. 3: S2) shows the corresponding electron diffraction pattern, which consists of a central hole with broad concentric rings around it. These results are typical of a very fine-grained material. The diffraction rings can be indexed on the basis of the cubic $\mathrm{ZnS}$ structure [12]. The inset also clearly shows the formation of lattice fringes, indicating the crystalline nature of the as-synthesized samples. The calculated average diameter based on HRTEM is not in agreement with that based on the XRD measurements. The rather large estimated experimental error results from the difficulty in determining the size of each nanocrystallite in the agglomerates. Moreover, XRD assumes regular atomic arrangement in the synthesized samples, whereas TEM considers the full size of the particles, including the non-crystalline part [13].

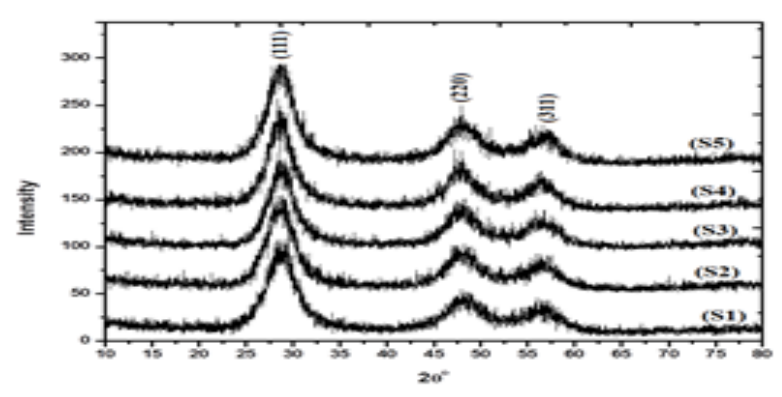

Fig. 2 - XRD patterns of ZnS nanoparticles prepared with various $\mathrm{Zn}^{2+}: \mathrm{S}^{2-}$ molar ratios and capped by PEG. S1: (1:0.5), S2: (1:0.7), S3: (1:1.5), S4: (1:2) and S5: (1:2.5)

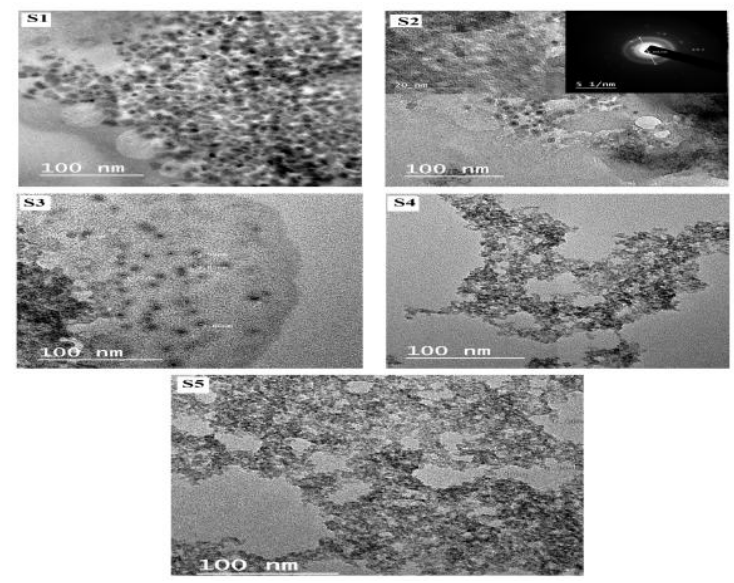

Fig. 3 - HRTEM images of ZnS nanoparticles prepared at different $\mathrm{Zn2+:S2-} \mathrm{molar}$ ratios and capped by PEG. S1: (1:0.5), S2: (1:0.7), S3: (1:1.5), S4: (1:2) and S5: (1:2.5). Insets in S2 show selected area electron diffraction (SAED) pattern and formation of lattice fringes. 
Figure 4 shows the optical absorption spectra of $\mathrm{ZnS}$ nanoparticles capped by PEG, prepared under different molars ratio of the precursors $\mathrm{ZnCl}_{2}$ and $\mathrm{Na}_{2} \mathrm{~S}\left(\mathrm{ZnCl}_{2}\right.$ constant and $\mathrm{Na}_{2} \mathrm{~S}$ variable): $\mathrm{S} 1$ (1:0.5), S2 (1:0.7), S3 (1:1.5), S4 (1:2), and S5 (1:2.5). It can be seen that there is no absorption band in the range $1100-450 \mathrm{~nm}$. There is a sudden increase in absorption below $350 \mathrm{~nm}$, with characteristic absorption shoulders found at 288, 300, 298, 293, and $289 \mathrm{~nm}$ for the samples S1, S2, S3, S4, and S5 respectively. The absorption peak is used to calculate the band gap of the nanoparticles [14]. The optical band gap was evaluated from the absorption spectrum, and the values are listed in Table 1 . In addition, the edge of the absorption band was calculated from the intersection of the sharply decreasing region of the spectra with the baseline, as in the case of Moffit and Eisenberg [15]. It can be seen that the optical band gap for the nanoparticles ranges from $4.13 \mathrm{eV}$ to 4.31 $\mathrm{eV}$, and the absorption wavelength exhibits a blue shift with respect to the bulk compound. The band gap of bulk $\mathrm{ZnS}$ is $3.70 \mathrm{eV}$ at $300 \mathrm{~K}$. Corresponding to the quantum confinement effect, electrons in the conduction band and holes in the valence band are spatially confined by the potential barrier of the surface. In order to confine the electrons and holes, the energy required for the lowest-energy optical transition from the valence band to the conduction band will increase, effectively increasing the band gap (Eg) [16]. This can be regarded as the exciton band for $\mathrm{ZnS}$ nanocrystals and proves the existence of $\mathrm{ZnS}$ nanoparticles [17]. The change in the blue shift with the ratio of the precursors indicates a greater reduction in the particle size with decreasing $\mathrm{Zn}^{2+}$ concentration. This can be attributed to some self-activated defect centers related to $\mathrm{Zn}$ vacancies. The shoulder of sample S2 at $300 \mathrm{~nm}$ was observed near the edge of the absorption band. This may be because the nanoparticles of sample S2 are larger than those of the other samples; therefore, the number of surface states is reduced. The quantum confinement effect allows one to tune the emission/excitation wavelength of the nanoparticles by tuning the particle size

The particle size is given by Eq. (3.2) the expression [18]

$$
D(E)=\frac{0.32-2.9 \sqrt{E_{g}-3.49}}{3.5-E_{g}},
$$

where $E_{g}$ is the band gap of the as-prepared samples in $\mathrm{eV}$ and is the diameter of the nanoparticles in $\mathrm{nm}$. In addition, the particle size can be calculated using effective mass approximation (EMA) [19, 20]. This approach has been used to explain blue shift and energy gap as functions of particle size. The following expression is derived from the effective mass model:

$$
\begin{aligned}
\Delta E_{g} & =E_{g}^{\text {nano }}-E_{g}^{\text {bulk }}=\frac{h^{2}}{8 r^{2}}\left(\frac{1}{m_{e}^{*}}+\frac{1}{m_{h}^{*}}\right)- \\
& -\frac{1.8 e^{2}}{4 \pi \varepsilon \varepsilon_{0} r}-\frac{4.890 e^{4}}{h\left(4 \pi \varepsilon \varepsilon_{0}\right)^{2}}\left(\frac{1}{m_{e}^{*}}+\frac{1}{m_{h}^{*}}\right)^{-1},
\end{aligned}
$$

where $E_{g}^{\text {nano }}$ is the band gap energy of the nanoparticle, which is determined from the UV-Vis absorbance

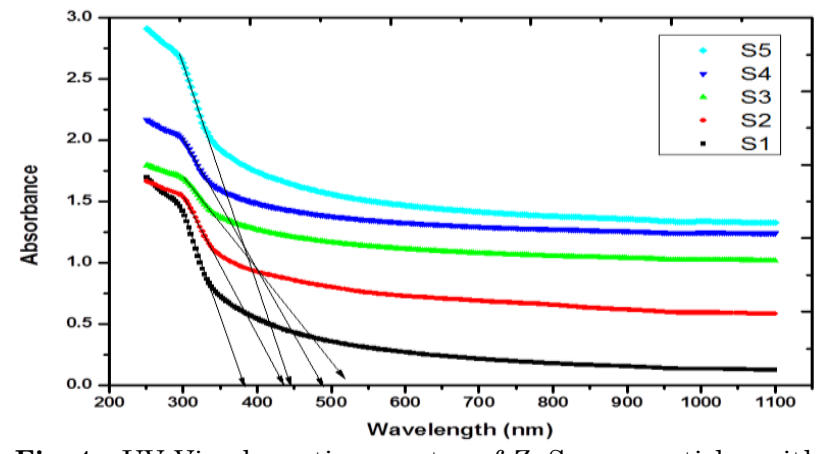

Fig. 4 - UV-Vis absorption spectra of $\mathrm{ZnS}$ nanoparticles with various $\mathrm{Zn} 2+: \mathrm{S} 2$ - molar ratios: $\mathrm{S} 1$ (1:0.5), S2 (1:0.7), S3 (1:1.5), S4 (1:2), and S5: (1:2.5).

Table 1: Optical band gap, blue shift, and particle size of $\mathrm{ZnS}$

\begin{tabular}{|c|c|c|c|c|c|c|}
\hline \multirow[t]{2}{*}{ 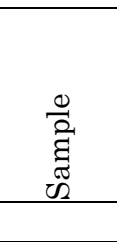 } & \multirow[t]{2}{*}{ 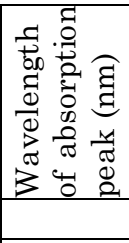 } & \multirow[t]{2}{*}{ 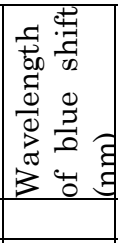 } & \multirow[t]{2}{*}{ 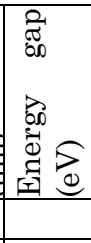 } & \multicolumn{3}{|c|}{ 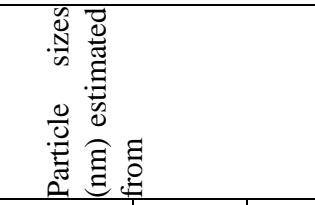 } \\
\hline & & & & HRTM & XRD & UV \\
\hline $\mathrm{ZnS}(\mathrm{S} 1)$ & 288 & 380 & 4.31 & 2.90 & 2.65 & 2.85 \\
\hline $\mathrm{ZnS}(\mathrm{S} 2)$ & 300 & 427 & 4.13 & 3.30 & 3.09 & 3.17 \\
\hline $\mathrm{ZnS}(\mathrm{S} 3)$ & 298 & 504 & 4.16 & 3.20 & 3.07 & 3.11 \\
\hline $\mathrm{ZnS}(\mathrm{S} 4)$ & 293 & 483 & 4.23 & 3.01 & 2.93 & 2.98 \\
\hline $\mathrm{ZnS}(\mathrm{S} 5)$ & 289 & 450 & 4.29 & 2.98 & 2.73 & 2.89 \\
\hline
\end{tabular}
nanoparticles prepared at different molar ratios of $\mathrm{ZnCl} 2$ and $\mathrm{Na} 2 \mathrm{~S}$ in PEG.

spectrum, $E_{g}^{\text {bulk }}$ is the band gap energy of bulk $\mathrm{ZnS}$ at room temperature $(3.7 \mathrm{eV}), h$ is Planck's Constant, $r$ is the particle radius $(\mathrm{m}), m_{e}^{*}$ is the effective mass of a conduction band electron in $\mathrm{ZnS}, m_{h}^{*}$ is the effective mass of a valence band hole in $\mathrm{ZnS}), e$ is elementary charge, $\varepsilon_{0}$ is the permittivity of free space, and $\varepsilon=8.3$ (the high frequency dielectric constant of $\mathrm{ZnS}$ ).

The calculated values are listed in Table 1. It is clear that the values of the diameter calculated from equations (3.2) and (3.3) are nearly equal and the optical band gap increases with decreasing particle size. On the other hand, the absorption spectra were fitted using the Lorentz model to quantitatively obtain the energy of the band-to-band transitions, as shown in Figure (5). According to this model, the two absorption bands $\mathrm{E}_{1}$ and $\mathrm{E}_{2}$ are attributed to the $1 \mathrm{~S}-1 \mathrm{P}$ and $1 \mathrm{~S}-1 \mathrm{~S}$ transitions of $\mathrm{ZnS}$ nanoparticles, respectively [21]. Obviously, the electronic properties of the $\mathrm{ZnS}$ nanoparticles are strongly affected by size in the entire measured frequency range. The optical absorption bands $\mathrm{E}_{1}$ and $\mathrm{E}_{2}$ were shifted to higher energy and the exciton band was blue shifted from the bulk value. This interpretation is agreement with that from theoretical investigations and previous work conducted by Chen et al., [21], Brus [22], and Rossetti et al. [23]. Similar behavior was reported by Lippens et al. [24], whereby the valence and conduction bands move down and up depending on the relative values of the effective mass of an electron $\left(m_{e}^{*}\right)$ and hole $\left(m_{h}^{*}\right)$. A considerable number of predictions have been made with regard to the effect of particle size on the electronic structure of $\mathrm{ZnS}$ close to the Fermi level [25, 26]. 

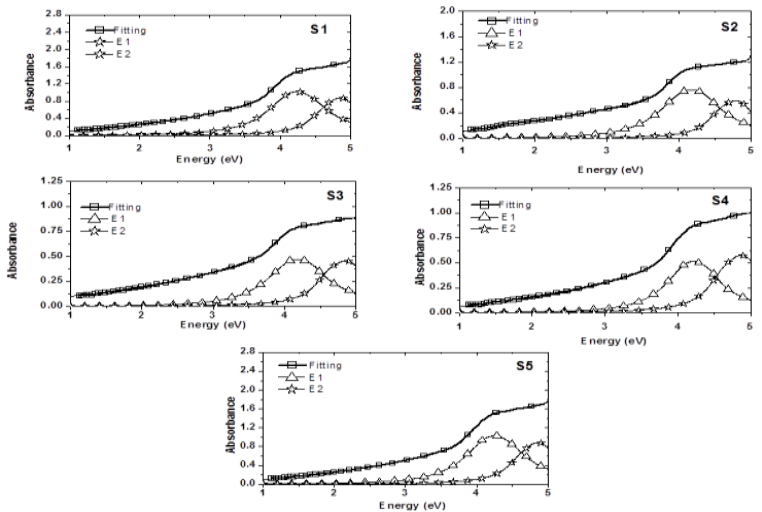

Fig. 5 - Lorentz function fit and fit components for $\mathrm{ZnS}$ nanoparticles synthesized with various $\mathrm{Zn} 2+\mathrm{S} 2-$ molar ratios: $\mathrm{S} 1$ (1:0.5), S2 (1:0.7), S3 (1:1.5), S4 (1:2), and S5 (1:2.5).

In accordance with the EMA model adopted by Ekimov et al. [26], the edge of the conduction band moves up while the edge of the valence band moves down. In the present study, three methods were used to calculate particle size: UV-Vis spectroscopy (i.e., position of the absorption peak), XRD, and direct HRTEM imaging. The effect of molar ratio on particle size calculated using these methods is shown in Figure (6). When XRD was used for size determination, no clear correlation was observed because of the significant strain-induced peak broadening. To estimate the correct particle size of the nanoparticles used in this study, we compare our UV-Vis data with the reliable TEM-based data.

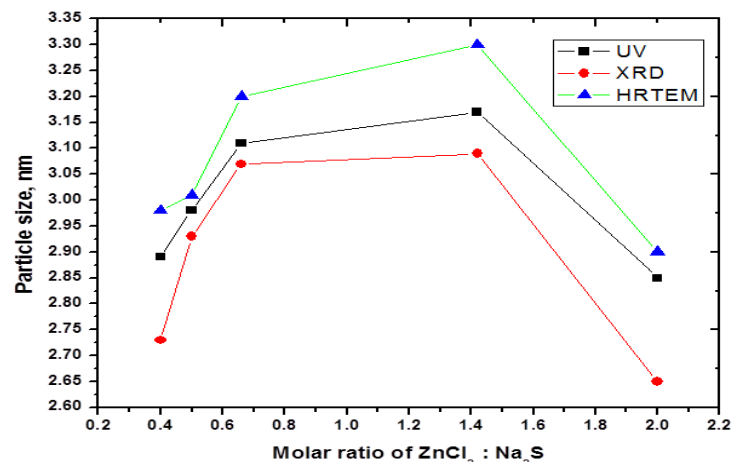

Fig. 6 - Particle sizes estimated using UV-Vis spectroscopy, $\mathrm{XRD}$, and HRTEM with different $\mathrm{Zn} 2+: \mathrm{S} 2$ - molar ratios of $\mathrm{ZnS}$ nanoparticles.

FTIR investigations were carried out to identify the $\mathrm{ZnS}$ nanoparticles prepared at different molar ratios of the precursors and capped by PEG. Figure (7) shows FTIR spectra in the range of $400-4000 \mathrm{~cm}^{-1}$. A broad and strong peak can be at $3300 \mathrm{~cm}^{-1}$. This band is assigned to the $\mathrm{OH}$ groups of PEG. The bands appearing at 2878,1464 , and $1343 \mathrm{~cm}^{-1}$ correspond to C-H stretching and bending vibrations. The bands due to $\mathrm{C}-\mathrm{O}$ stretching are merged in the very broad envelope centered on 1125 and $1000 \mathrm{~cm}^{-1}$. These two bands arise from $\mathrm{C}-\mathrm{O}, \mathrm{C}-\mathrm{O}-\mathrm{C}$ linkage stretching and $\mathrm{C}-\mathrm{O}-\mathrm{H}$ bending vibrations. The peak at $1094 \mathrm{~cm}^{-1}$ characterizes PEG; according to previous work conducted by Tunc et al. and Philip et al. [27-29], this peak appeared at 1000 $\mathrm{cm}^{-1}$. The shift of this peak towards higher frequency is attributed to the binding of $\mathrm{C}-\mathrm{C}-\mathrm{O}$ and $\mathrm{C}-\mathrm{C}-\mathrm{H}$ groups with $\mathrm{ZnS}$ nanoparticles. The broad peaks at 625 and $485 \mathrm{~cm}^{-1}$ are attributed to $\mathrm{ZnS}$ bonding with oxygen from the hydroxyl groups of PEG chains. Therefore, the FTIR spectra indicate the existence of van der Waals interactions between PEG chains and $\mathrm{ZnS}$ nanoparticles. The IR study confirms that the-C-O and $-\mathrm{OH}$ groups of PEG have a strong ability to bind with $\mathrm{ZnS}$ nanoparticles. The FTIR spectra of $\mathrm{ZnS}$ samples prepared at different molar ratios of $\mathrm{ZnCl}_{2}$ and $\mathrm{Na}_{2} \mathrm{~S}$ (S1S5) and capped by PEG are nearly similar, except for a negligible shift in the absorptions peaks owing to the interaction between $\mathrm{ZnS}$ and PEG.

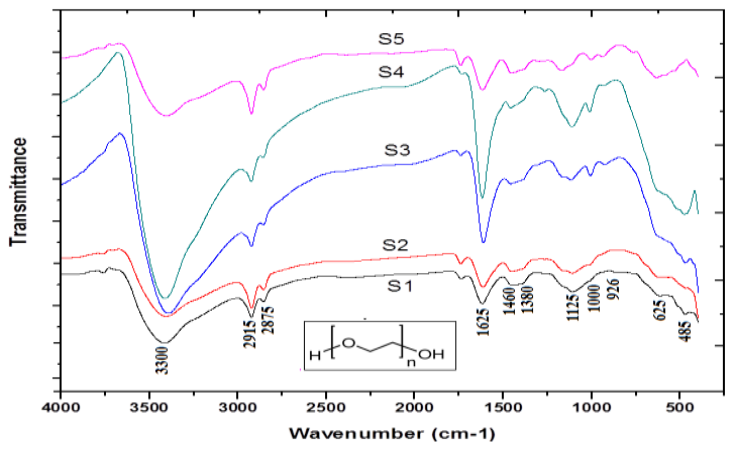

Fig. 7 - FTIR spectra for ZnS nanoparticles synthesized with various $\mathrm{Zn2+:S2-molar}$ ratios, S1 (1:0.5), S2 (1:0.7), S3 (1:1.5), S4 (1:2), and S5: (1:2.5), and capped by PEG.

\section{CONCLUSION}

ZnS nanoparticles of different sizes capped by PEG were successfully prepared. The crystallinity and phase of the synthesized nanoparticles were investigated via XRD and HRTEM, and the particle size was estimated to be in the range of $2.9-3.3 \mathrm{~nm}$. The particle size was varied by varying the concentrations of $\mathrm{Zn} 2+$ and $\mathrm{S} 2-$. Blue shift due to quantum size was shown using UV$\mathrm{Vis}$ spectroscopy. The chemical interaction between PEG and ZnS nanoparticles was discussed on the basis of FTIR data.

\section{ACKNOWLEDGEMENTS:-}

The authors would like to thank the Institute of Scientific Research and Revival of Islamic Heritage, Umm Al-Qura University (Project ID 43305026), for their financial support. 


\section{REFERENCES}

1. X. Fang, T. Zhai, U.K. Gautam, L. Li, L. Wu, Y. Bando, D. Golberg, Prog. Mater. Sci. 56, 175 (2011).

2. X.S. Fang, U.K. Gautam, Y. Bando, D. Golberg, J. Mater. Sci. Technol. 24, 520 (2008).

3. Y.F. Nicolau, M. Dupuy, M. Bruuel, J. Electrochem. Soc. 137, 2915 (1998).

4. R.N. Bhargava, D. Gallagher, X. Hong, D. Nurmikko, Phys. Rev. Lett. 72, 416 (1994).

5. B. Elidrissi, M. Addou, M. Regragui, A. Bougrine, A. Kachoune, J.C. Bernecde, Mater. Chem. Phys. 68, 175 (2001).

6. B. Bodo, P.K. Kalita, Proc. AIP. Conf. 1276, 31 (2010).

7. M. Jayalakshmi, M.M. Rao, J. Power. Sources 157, 624 (2006).

8. W. Park, J.S. King, C.W. Neff, C. Liddell, C.J. Summers, Phys. Stat. Sol. 229, 949 (2002).

9. F. Wei, G. Li, Z. Zhang, Mater. Res. Bull. 40, 1402 (2005).

10. R. Seoudi, A.A. Shabaka, M. Kamal, E.M. Abdelrazek, W. Eisa, Physica E 45, 7 (2012).

11. J.P. Borah, J. Barman, K.C. Sarma, Chalcognide Lett. 5, 201 (2008).

12. H. Hudlikar, S. Joglekar, M. Dhaygude, K. Kodam, J. Nanopart. Res. 14, 865 (2012).

13. C.N.R Rao, A. Muller, A.K. Cheetham, The Chemistry of Nanomaterials (Willey-VCH Verlag, Weinheim, 2005).

14. T.T.Q. Hoa, L.V. Vu, T.D. Canh, N.N. Long, J. Phys. 187, 01208 (2009).
15. M. Moffit, A. Eisenberg, Chem. Mater. 7, 1178 (1995).

16. A.P. Alivisatos, Nature 271, 933 (1996).

17. M.K. Naskar, A. Patra, M. Chatterjee, J. Colloid Interface Sci. 297, 271 (2006).

18. J.F. Suyver, S.F. Wuister, J.J. Kelly, A. Meijerink, Nano Lett. 1, 429, (2001).

19. R. He, X. Qian, J. Yin, H. Xi L. Bian, Z Zhu, Colloids Surf. A 220, 151 (2003).

20. L.E. Brus, J. Chem. Phys. 80, 4403 (1984).

21. W. Chen, Z.G. Wang, Z.J. Lin, Y. Xu, L.Y. Lin, J. Mater. Sci. Technol. 13, 397, (1997).

22. L.E. Brus, J. Chem. Phys. 79, 5566 (1983).

23. R. Rossetti, J.L. Ellison, J.M. Gibson, L.E. Brus, J. Chem. Phys. 80, 4464 (1984).

24. P.E. Lippens, M.L. Lannoo, Phys. Rev. B 39, 10935 (1989).

25. H. Xian, G.Z. Zhong, S. Tanaka, H. Kobayashi, Jpn. J. Appl. Phys. 28, L1019 (1989).

26. A.I. Ekimov, L. Efros, A.A. Onuschenko, Solid State Commun. 56, 921 (1985).

27. S Tunc, O Duman, Colloids Surf. A Physicochem. Eng. Asp. 37, 93 (2008).

28. D. Philip, Spectrochim. Acta A Mol. Biomol. Spectrosc. 75, 1078 (2010).

29. D. Philip, Spectrochim. Acta A Mol. Biomol. Spectrosc. 73, 650 (2009). 